\section{3 \\ $11+1=0$ \\ LA-6912-MS}

Informal Raport

UC.34

Issued: September 1977

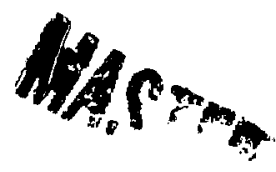

\title{
Hoat Transfer and Flow Friction in Fine Porous Media
}

W. A. Stayert
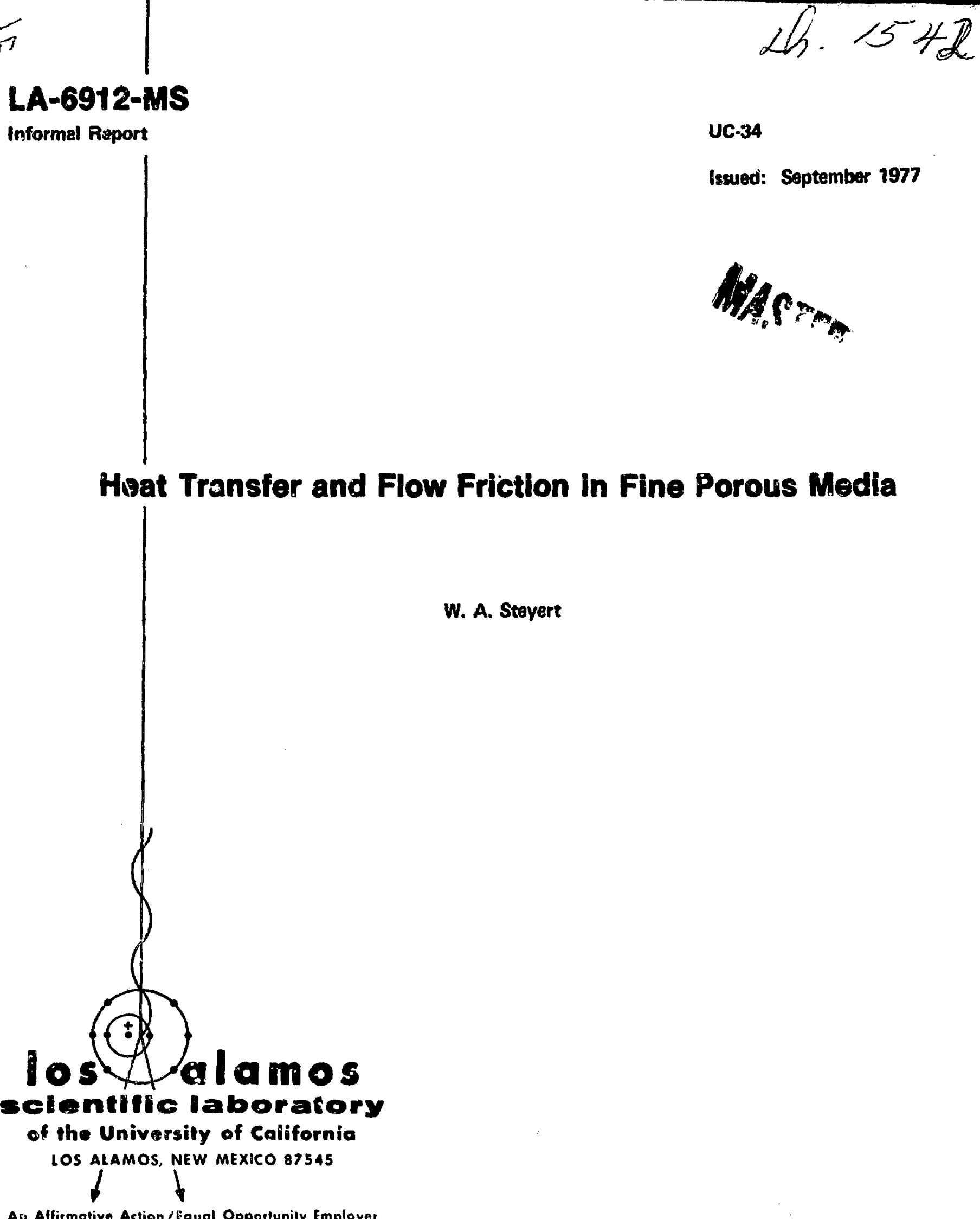
Printed in the United States of America. Available from National Technital Information Service

U.S. Deparyment of Commerce

5285 Port Royal Road Springfield VA 22161

Price: Printud Copy sto Microfiche $\$ 3.00$

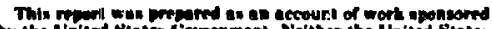

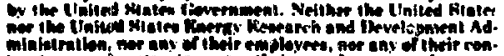

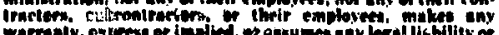

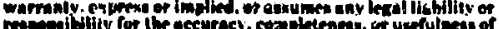

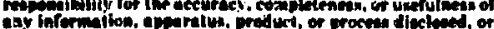

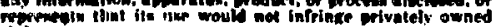
rifing. 


\section{HEAT TRANGEER AND FLOW FRICTION IN FINE POROUS MEDIA}

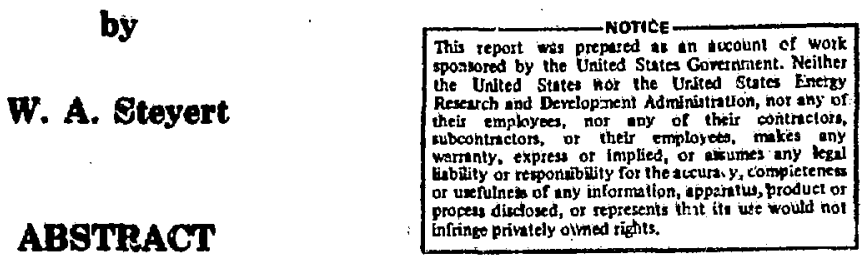

Fluid-flow friction factors and hent-tranofer coefficients are reported for fine screens (40,80, and 100 mesh) and for packed fine copper spheres (70 $\mu \mathrm{m})$. The fluids used are nitrogen and helium gae and svater. The observed values do not deviate Breatly from the values determined by scaling previovis measurements taken from much coasser structures.

\section{INTRODUCTION}

Most fluids are poor thermal conductors. To achieve good heat exchange between a flowing fluid and a solid surface, high fluid velocities are frequently employed. The resulting turbulent mixing provides the requirer' heat transfer between the main fluid stream and the solid surface. Unfortunately, the turbulence causes frictional fluid-flow losses by converting mechanical energy into heat. Sometimes, large pumps and compressors are needed to provide the llow.

If the fluids are forced to flow through very small channels in the appropriately constructed solid, each molecule of the fluid is brought close to the solid, and heat need flow only short distances through the poorly conducting fluid. Pressure drops are kept small by choosing a suitsble overall geometry so that fluid flow through the surfaces is slow.

\section{OBJECTIVES}

The aims of this research are to measure pressure drops in fluids moving through small clannels in metals and to measure heat-transfer coefficients in the same geometries, in preparation for magneticrefrigeration tests. The literature gives pressure drops and heat-transfer coefficients for larger versions of some of our geometries and provides scaling laws with which to calculate values for some of our geometries. However, because fluid-flow scaling laws are not always accurate far: outeide of the measureme.it range, actual measurements are needed. Another objective is to learn the pitfalle in. volved in making accurate heat-transfer measurements, because heat transfer will be the main problem in magnetic-refrigeration technology.

The construction and testing of cryogenic cousnterflow htat exchangers with finely divided metal surfaces will demonstrate these heat-transfer methods before they are used in magneticrefrigeration cycles.

\section{SURFACES TO BE MEASURED}

Pressure drops and heat-transfer coefficients were measured for 40-, 80-, and 100-mesh (US Standard) copper screen (Fig. 1). The finest mesh, low-cost copper screen available is 100 mesh from Buffalo 

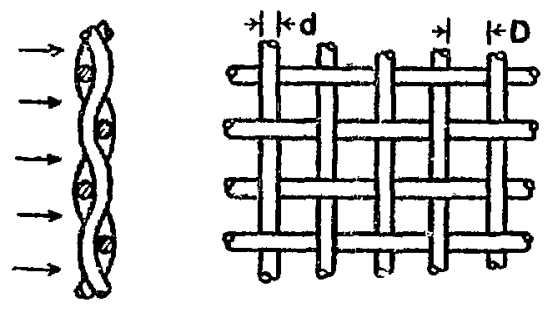

Fig. 1.

Screens of wire diameter $d$ and opening size $D$.

Wire Works* (screen finer than 100-mesh copper requires specialized construction methods).

The pressure drop across a tube filled with spheres of 0.32 - and $0.48-\mathrm{cm}$ diam was neasured, as was the pressure drop across a plate $0.43 \mathrm{~mm}$ thick of $60-\mu \mathrm{m}$-diam sintered copper spheres ${ }^{* 4}$ (Fig. 2 ).

Because thin plates of fine particles are vary fragile, we used 60-mesh copper screen as a base and ciffusion-bonded (sintered) to it rough $1.05-\mu \mathrm{m}$ diam copper particles and $70-\mu \mathrm{m}$-diam copper spheres:* to form beds. Pressure drops were measured for the $1.05-\mu \mathrm{m}$ particles and the $70-\mu \mathrm{m}$ spheres, and heat-transfer coefficients were measured for the $70-\mu \mathrm{m}$ spheres.

After the above measurements were completed, we found that the screens were preferable to the particle beds when we compared the ratio of heat transfer, hA' (W/K), to pressure drop, $\mathbb{P}(\mathrm{Pa}$ or dyn $/ \mathrm{cm}^{2}$ ), for a given fluid mass-flow rate, $\mathrm{G}\left(\mathrm{g} / \mathrm{cm}^{2} \cdot \mathrm{s}\right)$, and frontal area of surface, A. This is attributable to the open structure of the screen. We felt that the open nature of the screen could be maintained but the heat-transfer area increased if the screen had a light "dusting" of spheres diffusionbonded to it. Some 100- and 40-mesh screens were dipped into a dilute solution of organic vacuum grease in toluene. When the toluene evaporated, the screens were dusted with $70-\mu \mathrm{m}$ copper spheres, which adhered to the residual grease in more or less of a monolayer. The screens were then heated to $1223 \mathrm{~K}$ in $0.013 \mathrm{~Pa}\left(10^{-4}\right.$ torr) of dry-air pressure for about $4 \mathrm{~h}$ to bond the spheres to the screens (the air was dry to improve the low-temperature thermal

\footnotetext{
*P. O. Box 129-T, Buffalo, NY 14240.
}

**Metco 55 copper spheres for flame-sprayed coaiings. Metcu, Inc., 1105 Prospect Ave., Westbury, NY 11590.

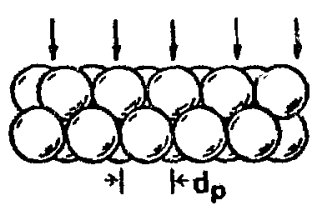

Fig. 2.

Idealizea array of spheres of particle diameter $d_{\mathfrak{p}}$. The particles in our plate were randomly packed.

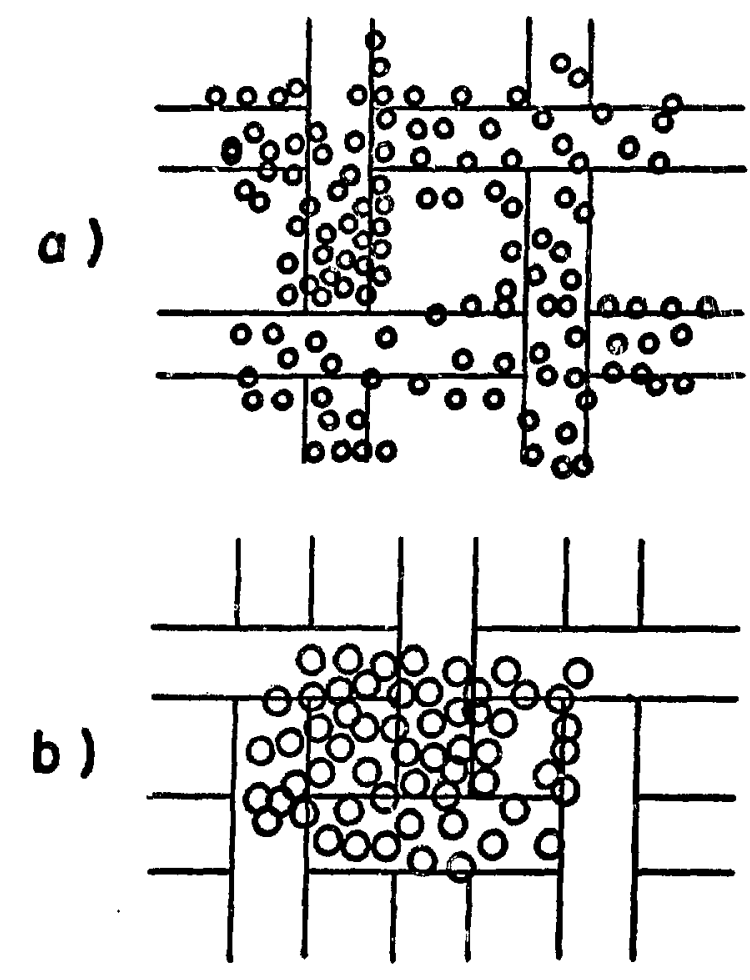

Fig. 3.

c) Spheres $(70 \mu \mathrm{m}$ ) bonded to a copper 40 mesh screen in an incompiete monalayer.

b) Spheres ( $\% 0^{\circ} \mathrm{m}$ ) bonded to a copper 100 . mesh screen, filling many of the screen openings.

conductivity of the copper $\left.{ }^{1}\right)$. The resulting screen (Fig. 3) had a little less than a monolayer on the 40 mesh, and a little more than a monolayer on the 100-mesh screen (spheres almost filling most of the screen openings). Heat-transfer coefficients were measured for the uncoated and coated 40-mesh 


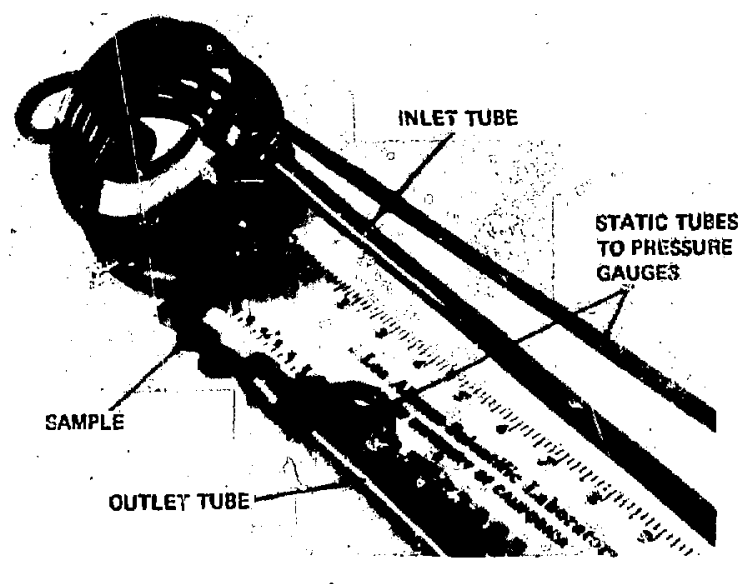

Fig. 4.

Pressure-drop apparatus (disassembled). Small-diameter tubes connect to the pressure and reference sides of a differential pressure gauge. Incoming gas goes through the copper coil for precooling if the experiment is carried out at liquid-nitrogen temperature.

screen. Pressure drops and heat-transfer coeffi:ients were measured for the 100 -mesh spliere-coated screen.

\section{PRESSURE-DIOP MEASUREMENTS}

\section{A. Pressure-Drop A.pparatue}

The pressure-drop apparatus is shown in Fig. 4. An inlet tube supplies the fluid (nitrogen or helium gas or water) that flows through the material being tested. The flow rate is measured by running the exit gas through a meter or the water into a beaker of known volume. The flow rate is given by the volume divided by the elapsed time.

The pressure drop across the material is measured with a $200-\mathrm{mm}$ or $50-\mathrm{mm}$ Wallace and Tiernan* gauge or from the height differential in a U-tube of water. The inlec pressure is measured relative to the outlet pressure in static ines attached to the pressure lines $2 \mathrm{~cm}$ on either side of the sample.

*Division of Pennwalt Corp., 25 Main Street, Belleville, NJ 07109 .

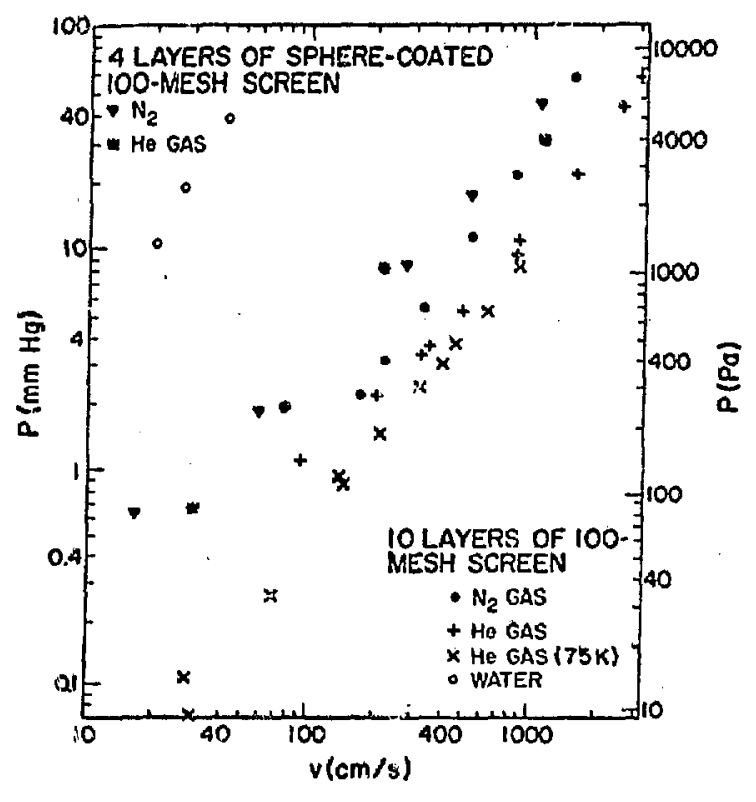

Fig. 5.

Pressure drops measured for one 75- $K$ and three room-temperature fluids flowing through copper screen alone and screen coated with 70 $\mu \mathrm{m}$ spheres. For each sereen $d=0.011 \mathrm{~cm}$ and $D=0.014 \mathrm{~cm}$. Each layer is $0.025 \mathrm{~cm}$ thick. The porosity, of the screen alone, $\alpha_{t}$ bused on projected frontal area, is 0.31 .

For the screens and the fine spheres the sample was a disk about $1.1 \mathrm{~cm}$ in diameter (exact areas, which differ slightly from material to material, are used in the data analyses). When multiple layers of screen were studied, they : were randomly oriented and lightly pressed one on top of another. The terscreen spacing was typically half of the screen thickness. Separate tes's showed that this distance was not significant. For the larger spheres, the pressure drop was measured in a tube $0.9 \mathrm{~cm}$ in diameter and $7.6 \mathrm{~cm}$ long filled with the spheres.

\section{B. Pressure-Drop Results}

Figurer 5.9 present the pressure-drop results. The pressure drop $\mathbf{P}$ in the system before a sample was inserted was measured and found to be less than $5 \%$ of the pressure Arop through any of the materials; 


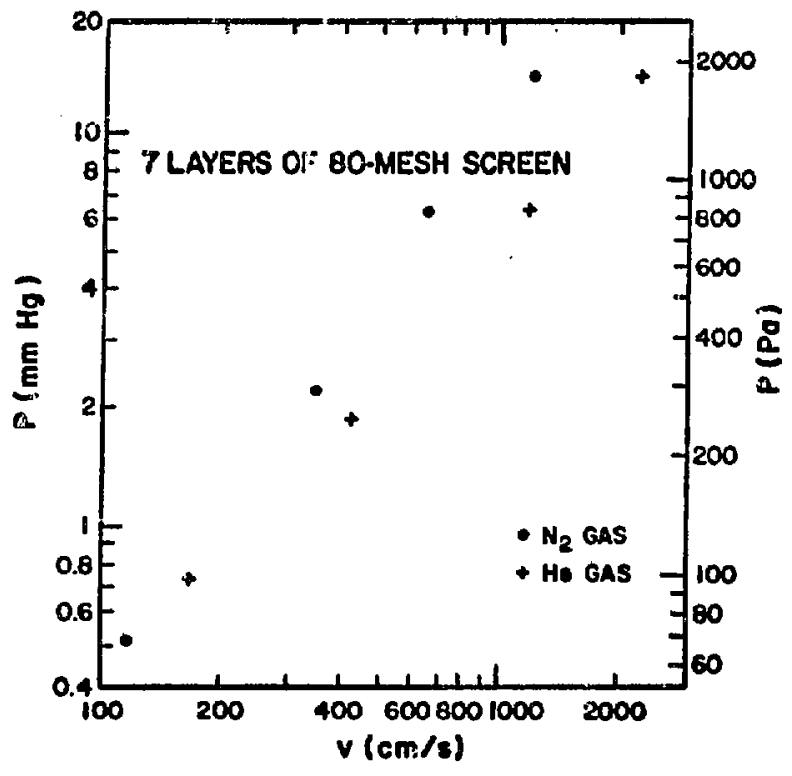

Fig. 6.

Pressure drops measured for two roomtemperature gasps flowing through copper screen. Far each screen $d=0.0135 \mathrm{~cm}, D=$ $0.0165 \mathrm{~cm}$, and the screen thickness is 0.035 $\mathrm{cm}$. The porosity, $\alpha_{\mathrm{t}}$, is 0.30 .

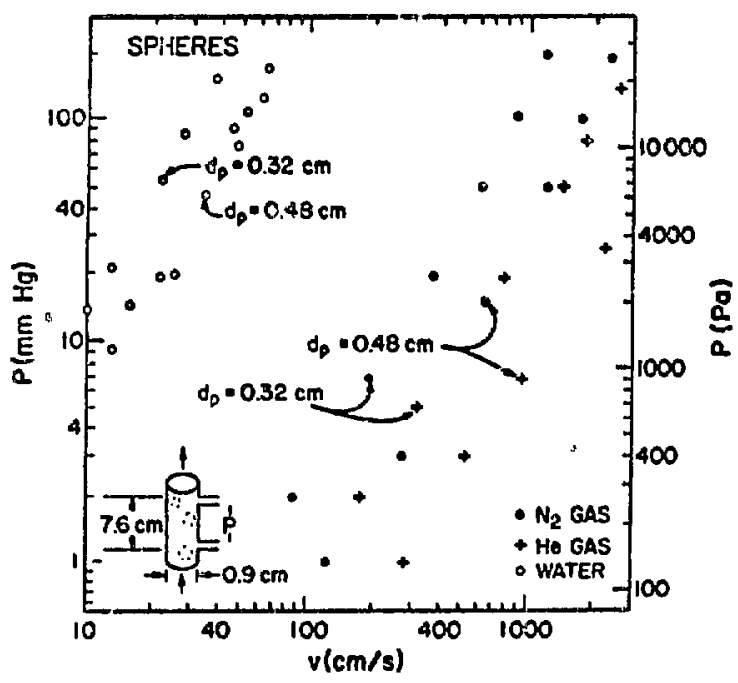

Fig. 7.

Pressure drops measured for three roomteniperature fluids flowing through a tube of spheres of diameter $d_{p}$ (see inset). The porosity $\alpha=0.39$ for $d_{p}=0.32$ cm and $\alpha=0.49$ for $d_{p}=$ $0.48 \mathrm{~cm}$.

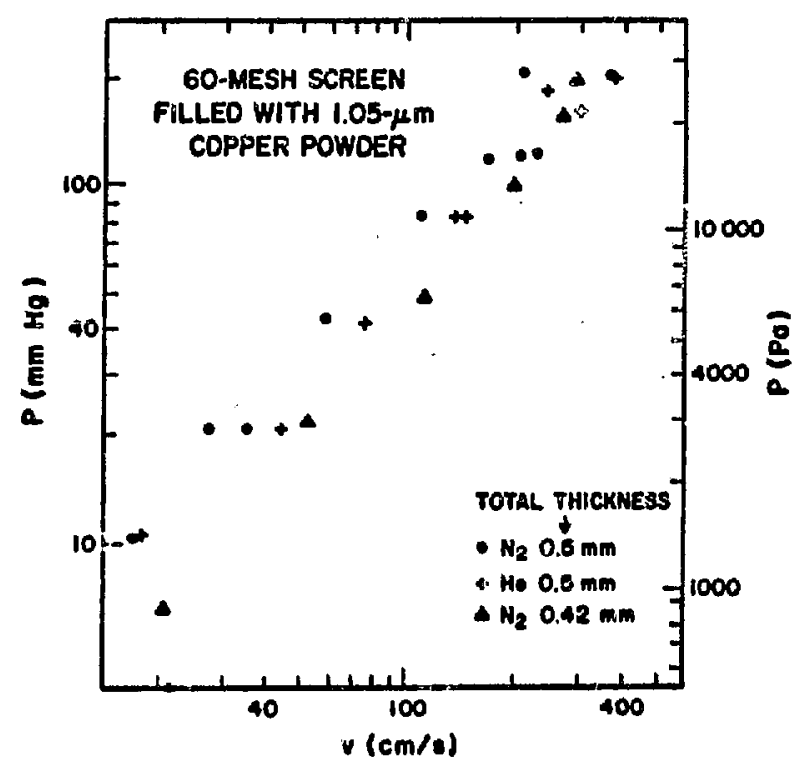

Fig. 8.

Pressure drops measured for roomtemperaiure fluid's flowing through copper screen filled with plowder for two thicknesses of the resulting matrix. The surprisingly low flow impedance may be caused by leakage through the irregularities in the matrix and around the O-rings in the sample holder.

and so this correction was neglected. Thus, the pressure drops plotted are those read directly from the gauge or U-tube. A slight correction to the gas velocity was needed. The superficial velocity* $v$ is given by

$v \approx \frac{V}{A t}$.

where $\mathrm{V}$ is the volume of gas that has flowed through an area $A$ of tho screen in time $t$. Actually,

$y=\frac{\operatorname{At}(1+2 \sqrt{1160)}}{V}$

"As is common practice in heat-exchange work, we used superficial velocities; that is, velocities deduced assuming that the sample was not in the oystem. 


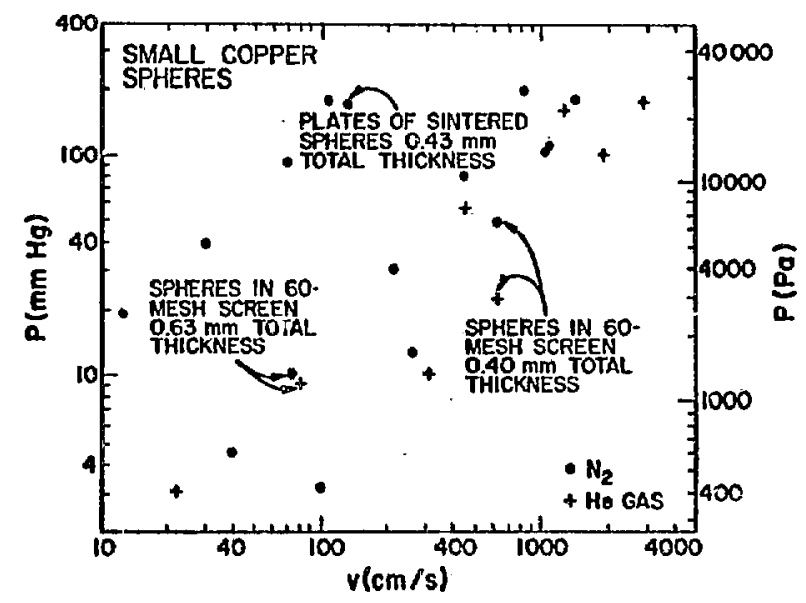

Fig. 9.

Pressure drops measured for room. temperature fluids flowing through copper screen filled with $70-\mu m$ spheres for two thicknesses of the resulting matrix. Porosity (based on the measured void fraction) of the screen-sphere composite, $\alpha$, is 0.5. Also, pressure drops for sintered plates $0.43 \mathrm{~mm}$

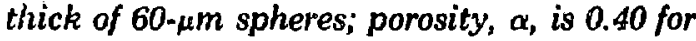
these plates.

where the factor in parentheses corrects for the fact that, as the gas moves through the material, the average gas density is somewhat higher than it is at atmospheric pressure of $77300 \mathrm{~Pa}$ ( 580 torr), and thus the gas velocity is lower. This correction is not needed for water [Eq. (1) becomes an equality].

Figure 10 shows the pressure-drop results plotted in dimensionless triction factor $f$. For a screen, Chemical Engineers' Handbook ${ }^{2}$ Eq. 5-100 (translated to SI or cgs units*) gives

$p=\frac{n}{c^{2}}\left(\frac{1-\alpha_{f}^{2}}{\alpha_{f}^{2}}\right)\left(\frac{v^{2} \rho}{2}\right)$.

where $\mathbf{n}$ is the number of layers of screen the fluid passes through, $\alpha_{q}$ is the porosity based on the projected free frontal area $D^{2} /(d+D)^{2}$ from Fip. 1, $\rho$ is

-The pressure drop formulas used here are volid in any consistent set of metric units. In English units a facior of if (the acceleration of gravity at the earth's surface) is necessary.

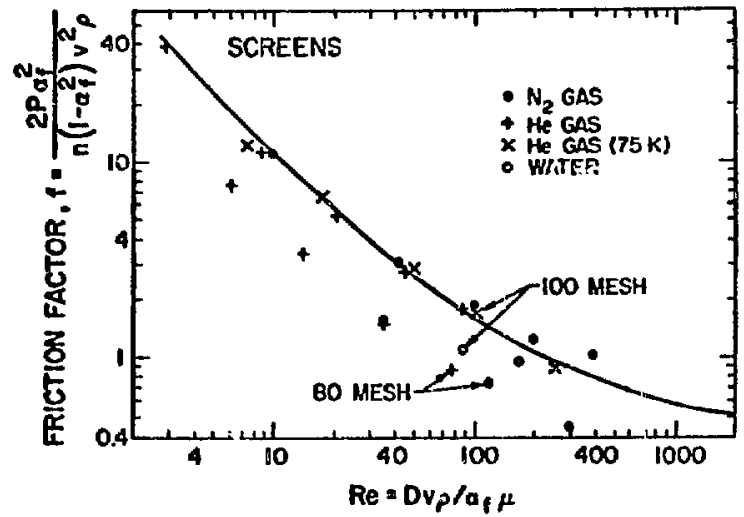

Fig. 10.

Friction factor us Reynolds number as defined by Ref. 2 for screen. Solid curve is from the results in Ref. 2.

the fluid density, and $\mathrm{C}$ is an empirically determined dimensiculess constant. We define

$$
f \equiv \frac{1}{c^{2}} \equiv \frac{p}{n\left(\frac{1-\alpha_{f}^{2}}{a_{f}^{2}}\right)\left(\frac{v^{2} \rho}{2}\right)} \text {. }
$$

Figure 5.44 of Ref. 2 gives $\mathrm{C}$ as a function of the Reynolds number,

$\operatorname{Re}=D v p / \alpha_{f} \mu$,

where $\mu$ is the fluid viscosity in $\mathrm{Pa} \cdot \mathrm{B}$ (SI) or poise = $\mathrm{dyn} \cdot \mathrm{s} / \mathrm{cm}^{2}=\mathrm{g} / \mathrm{cm} \cdot \mathrm{s}$ (cgs). Figure 10 shows $\mathrm{f}$ calculated from the measured values in Eq. (4) and also shows the curve of $f=1 / C^{2}$ from Fig. 5-44 of Ref. 2.

A convenient tabulation of pressure drops in particle beds is given in Ref. 3. Here the friction factor $f$ is defined as

$f=\frac{P d p^{\alpha^{3}}}{L \rho v^{2}(1-\alpha)}$

where the porosity $\alpha$ is the ratio of void to filled volume in the bed, $d_{p}$ is the spherical-particle diameter $_{3}$ and $L$ is the dimension of the bed in the flow direction. In this formulation 


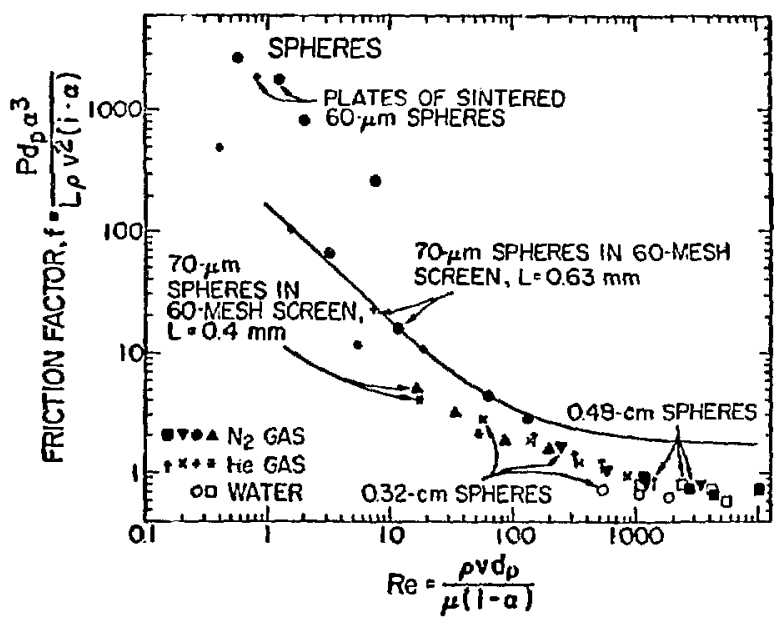

Fig. 11.

Friction factor us Reynolds number for small and large spheres with three fluids at room temperature. Curve is the data of Ref. 3.

$R e \equiv \frac{\rho v d p}{\omega(1-\alpha)}$.

Figure 11 shows $f$, calculated from the measure values, versus $R e$.

\section{HEAT-TRANSFER MEASUREMENTS}

\section{A. Heat-Transfer Apparatus}

Figure 12 shows the heat-transfer anparatus. The sample being tested was heated by an electrical current (50-100 A). The fluid was heated as it flowed through the material. The fluid inlet and exit temperatures were measured by copper-constantan thermocouples $(0.008-\mathrm{cm}$ wire diameter) and recorded on a four-pen chart recorder $(500 \mu \mathrm{V}$ full scale $)$. The thermocouples measuring inlet and outlet temperatures were soldered to passive 100-mesh screens in the fluid flow. The screen positioning assured that the thermocouple and the fluid were the same temperature.

The sample temperature was measured at two locations by thermocouples soldered to the sample. The solder bits were small (less than $1 \mathrm{~mm}$ in diameter) to minimize flow disruption near the thermocouples. The silk-insulated thermocouple wires

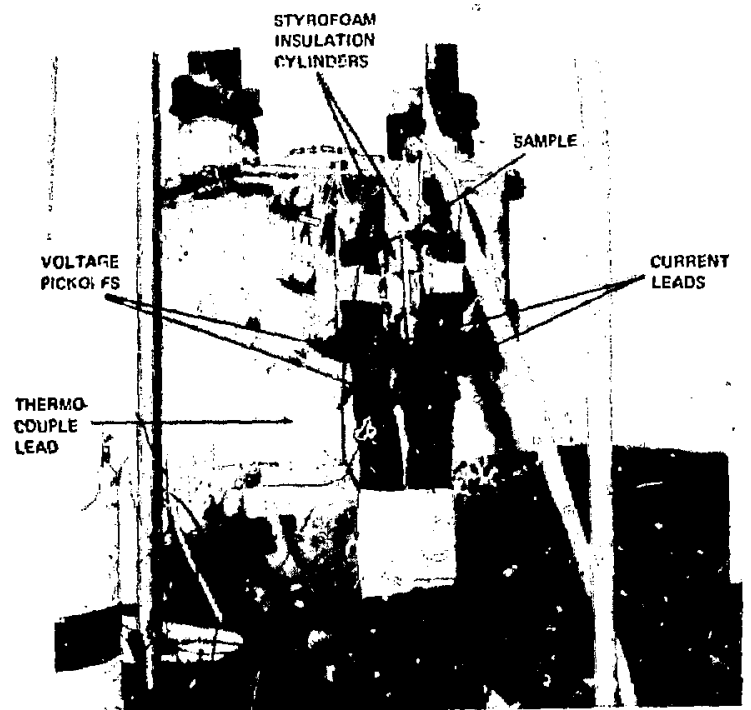

Fig. 12.

Heat-transfer apparatus. The fluid is heated as it moves upward through the electrically heated screen. Fluid flows through a roughly 1$\mathrm{cm}$-diam disk of the material. Styrofoam cylinders $1 \mathrm{~cm}$ long with $1-\mathrm{mm}$ walis insulate the gas stream on each side of the sample.

exiting the experimenta? area were glued to the sample to assure that the sample temperature was measured as accurately as possible. It was important to run the thermocouple wires roughly perpendicular to the applied voltage, which heated the sample, to minimize current leakage through the silk insulation. The leakage could cause erroneous signals. The current through the sample was reversed during each measurement to identify and correct for any such erroneous effect. The voltage applied to the sample precluded the use of the sample itself as the copper side of the thermocouple. An estimate of the sample temperature was also deduced by measuring the voltage across the screen as a function of current; the copper resistance is a measure of the sample temperature.

The fluid-flow rate was again measured by running the exit gas through a meter or the water into a beaker of known volume. The thermal heat-transfer coefficient $h$ was deduced as a function of flow rate. 


\section{B. Heat-Transfer Data Analyses}

Consider a fuid fowing through a uniform matrix at temperature $T_{m}$ es shown in Fig. 13. Consider a frontal aree $A$ of the mutrix with thickness $L$. Consider the matrix to have total heat-exchange area $A^{\prime}$ and to have heat-transfer coefficient $b$ $\left(W / \mathrm{cm}^{2} \cdot \mathrm{K}\right)$. If the fluid is flowing with superficial velocity $v$ and has specific heat $C_{p}(J / g \cdot K)$ and densicy $\rho$, then for a gas temperature $T(x)$ at position $x$ in the motrix,

$$
C_{p} \rho \vee A \frac{d T(x)}{d x}=h \frac{A^{\prime}}{L}\left[T_{m}-T(x)\right] .
$$

or

$T(x)=T_{m}+\left(T_{1}-T_{m}\right) \exp \left(-h A^{\prime} x / L C_{p} p \vee A\right)$

where $T_{1}$ is the fluid temperature at the input, $x=0$, of the matrix. The output fluid temperature at $\mathrm{x}=$ $L, T_{0}$, is given by

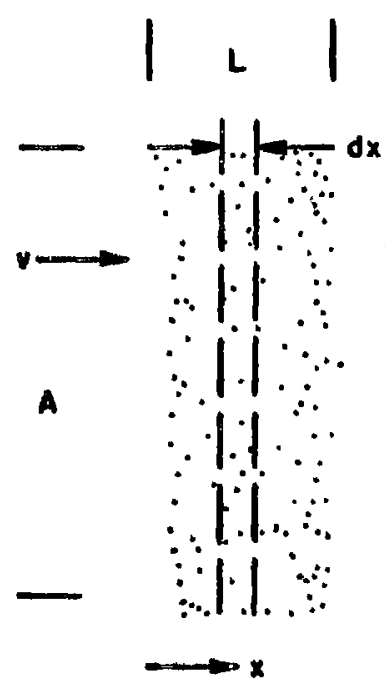

Fig. 13.

Schematic diagram of heat transfer to a fluid flowing at superficial velocity $v$ through a matrix that is of frantal area $A$, thickness $L$, and uniform composition and temperature.

$$
T_{0}=T_{w}+\left(T_{i}-T_{m}\right) \exp \left(-h A 1 / C_{p} \rho v A\right) .
$$

or

$h=\frac{C_{p} p V A}{A^{\top}} \ln \left(\frac{T_{m}-T_{i}}{T_{m}-T_{o}}\right)$.

Another way to arrive at $h$ is to calculate

$M A^{\prime}\left[T_{m}-\left(\frac{T_{i}+T_{0}}{2}\right)\right]=c_{p}$ PVA $\left(T_{0}-T_{i}\right)$

where the left-hand side of this equation is the heat flow from the matrix to the fluid at average temperature $\left(T_{1}+T_{0}\right) / 2$, and the right-hand side is the power input to heat the matrix. Equations (11) and (12) are nearly the same, as a series expansion of $h$ in the measured temperatures, $T_{1}, T_{0}$, and $T_{m}$, shows. However, because Eq. (12) is only an approximation, we used Eq. (11) to analyze the data.

\section{Heat-Transfer Results}

Figures 14-17 present the measured heat-transfer coefficients $h$ in dimensionless form as a function of the superficial mass-flow velocity, $\mathrm{G}\left(\mathrm{g} / \mathrm{cm}^{2} \cdot \mathrm{B}\right)$. The measurements were made at room temperature; each plotted point typically represents data taken at several different power levels.

Figures 14-17 show the heat-transfer results in plots similar to those of Figs. 7-8 and 7-10 of Ref. 4 . Here $\mathrm{hPr}^{2 / 3} \alpha / \mathrm{GC}_{b}$ is plotted againgt the Reynolds number, defined as

Re $=D_{h} G / \mu \alpha$.

Pr is the Prandtl number $C_{p} / / h_{0}$ where $k$ is the thermal conductivity; $h / G^{\prime}$ is sometimes called the Stanton number; and

$G=\dot{D} / A=v \rho$ 


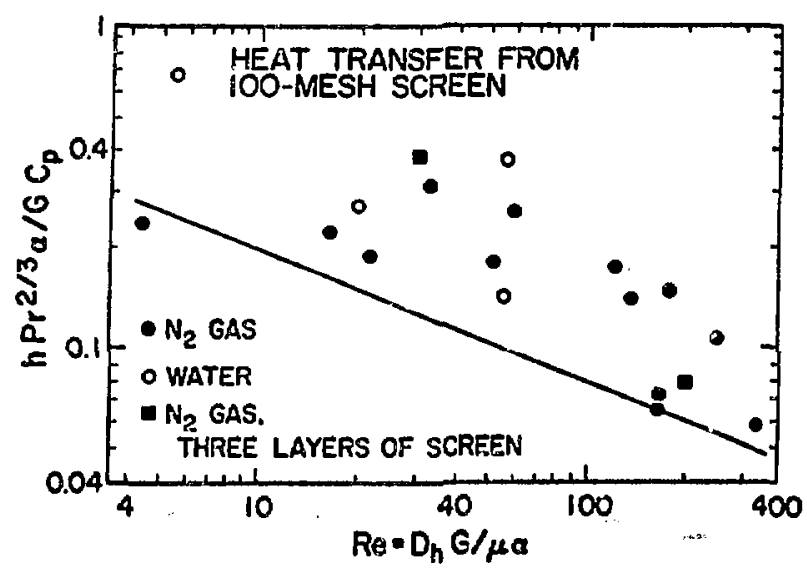

Fig. 14.

The dimensionless quantity $h \mathrm{Pr}^{2 / \mathrm{a}} \alpha / G C_{\mathrm{p}}$ us Reynolds number for 100-mesh screens ( $d=$ $0.011 \mathrm{~cm}$ and $D=0.014 \mathrm{~cm}$ ). The screen porosity, $\alpha$, is 0.49 [Eq. (15)], and the hydraulic diameter, $D_{\mathrm{h}}$ is $0.021 \mathrm{~cm}[E q .(16)]$. The line is from the results of Ref. 5 , which were quoted by Ref. 4 for 60-mesh screen with $\alpha=0.6$. One layer of screen was used, except as indicated; the work with three layers was not as accurate because, with the better heat transfer, the small $\Delta T$ between the screen and the outlet fluid was difficult to measure.

where $\dot{m}$ is the total mass-flow rate through super. ficial area A. Because $\alpha$ is not fully defined in Ref. 4, we go to the original reference ${ }^{6}$ where $\alpha$ is defined as the ratio of the total volume of void to the tota! volume of matrix. For a screen we take the thickness as $2 \mathrm{~d}$ to calculate

$\alpha=1-\frac{\pi}{4} \frac{d}{D+d}$.

Reference 5 gives the hydraulic diameter $68 D_{h}=$ $4 \alpha / \beta$, where $\beta$ is the ratio of the surface of voids to the total volume of the matrix, which we calculate as $\pi /(\mathrm{D}+\mathrm{d})$ for screen. Then

$D_{h}=1.27 D+0.27 d$.

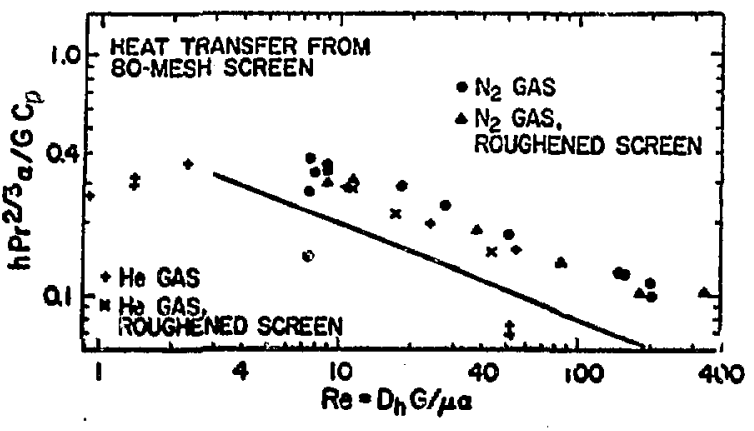

Fig. 15.

The dimension less quantity $h P^{s / 3} \alpha j G C_{\mathrm{p}}$ us Reynolds number for 80-mesh screen (d = $0.0135 \mathrm{~cm}$ and $D=0.0165 \mathrm{~cm}$ ), $\alpha=0.65$ and $D_{\mathrm{h}}=0.025 \mathrm{~cm}$. The roughened screen was treated with emery cloth in a futile atternpt to increase $h$.

We use Eqs. (14) and (16) in our plots of heat transfer from screen (Figs. 14 and 15).

Heat transfer through packed beds of spheres is estimated in Ref. 3 as

$\mathrm{Nu}=0.80 \mathrm{Re}^{0.7} \mathrm{Pr}^{1 / 3}$

for $\alpha=0.37$ and Re between 500 and $50000 . \mathrm{Nu}$ is the dimensionless Nusselt number, $h_{p} / k$, and $R e=$ $\mathrm{Gd}_{\mathrm{p}} / \mu$. We measure for Re between 0.16 and 40 and compare our results with those of Ref. 5 , which go to Re as low as 20 in beds of packed spheres. Reference 5 has

$\frac{h \alpha}{\mathrm{GC}_{\mathrm{p}}}=0.21 \mathrm{Re}^{-0.31} \mathrm{Pr}^{-1}$

where

$\operatorname{Re}=D_{h} G / \mu \alpha$

and

$D_{h}=4 \alpha / \beta$ 


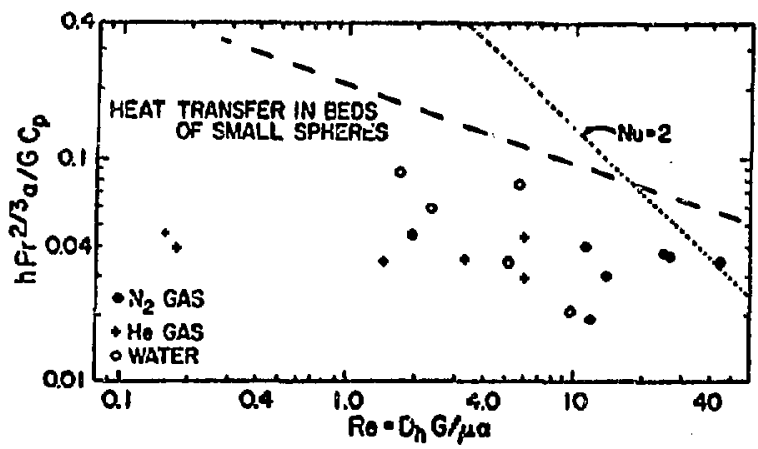

Fig. 16.

The dimensionless quantity $h P r^{\mathrm{s} / \mathrm{a}} \alpha / G C_{\mathrm{p}}$ us Reynolds number for 60-mesh copper screen filled with 70- $\mu \mathrm{m}$ copper spheres $0.63-\mathrm{mm}$ - and $0.40-\mathrm{mm}$-thick matrix results are the same within the scatter and are not distinguished). The porosity, $\alpha$, is 0.5 , and the hydraulic diameter, $D_{\mathrm{h}}$ is $0.0048 \mathrm{~cm}[E q$. (20)]. The dashed line is an extrapolation of data from Ref. 5 that were measured with $0.21-\mathrm{cm}$ spheres for Re between 25 and 500. Experimental uncertainty in these results is large because the excellent heat transfer to the fluid makes the screen-to-outlet-fluid temperature difference small and thus difficult to measure accurately. We do not consider the large difference between the measured and tho expected $h$ ai lower Re nccessarily real.

We calculate and use for spheres

$D_{h}=2 d p \frac{a}{3(1-a)}$.

For the heat-transfer results from small spheres (Fig. 16) we plot $h \mathrm{Pr}^{2 / 3} \alpha / \mathrm{GC}_{\mathrm{p}}$ versus $\mathrm{Re}$ [Eq. (19)] as in Reference 4 . The scaling law here differs by a factor of $\mathrm{Pr}^{\mathrm{i} / 3}$ from that of Eq. (18). Because the dimensionless $\mathrm{Pr}$ is $\sim 1$ for most cases of interest, we ignore this small difference. (The available data are unable to distinguish between $\operatorname{Pr}^{2 / s}$ and $\operatorname{Pr}^{1}$ scaling).

In addition to comparing our ineasurements with the results in Ref. 5, we comparo them with the estimate $^{6}$ that

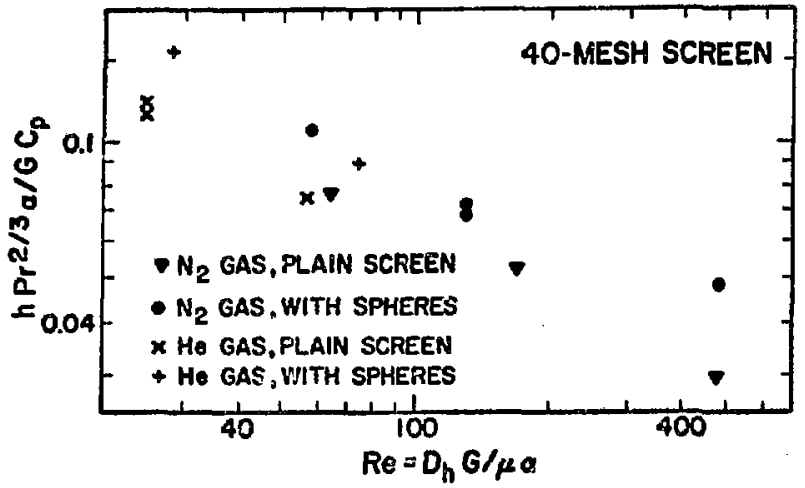

Fig. 17.

The dimensionless quantity $h P^{2 / d} \alpha / G C_{p}$ us Keynolds number for 40-mesh screen, $\alpha=0.52$, $d=0.036 \mathrm{~cm}, D+d=0.063 \mathrm{~cm}$, and $D_{\mathrm{h}}=$ $0.040 \mathrm{~cm}$. The 40-mesh screen coated with an incomplete monoinyer of 70-4m copper spheres (sintered to the wires) was also measured. The roughly $25 \%$ increase in $h$ is probably, but not certainly, real. The values used for $\alpha, D_{\mathrm{h}}$ area, etc. for the coated and uncoated screen were taken as identical to allow a direct comparison of the results.

$N u=h_{p} / k=2$

for low Re. (This is estimated as a minimum; for Re $\gtrsim 1$, Nu should increase appreciably). Thus, for low Re we expect (using $\operatorname{Pr}=\mathrm{C}_{n} \mu / \kappa$ and Ejs. (19) and (21)

$\frac{\mathrm{hPr}^{2 / 3} \alpha}{G C_{\mathrm{p}}}=\frac{2 k}{\mathrm{~d}_{\mathrm{p}}} \frac{\mathrm{Pr}^{2 / 3} \alpha}{G C_{\mathrm{p}}}=\frac{4}{3} \frac{\alpha}{\operatorname{RePr}^{1 / 3}(1-\alpha)}$.

Taking $\alpha=1 / 2$ and $\operatorname{Pr} \approx 1$, we get the dotted curve shown in Fig. 16.

Figure 17 shows the heat-transfer data for the 40 mesh screen and the screen coated with an incomplete monolayer of $70-\mu \mathrm{m}$ copper spheres. It was not possible to measure actual heot contact area $A^{\prime}$ with the spheres on the screen wires. Because we were primarily interested in a direct comparison with the 
uncoated screen, $h$ was calculated from the experimental values of $h A^{\prime}$ taking $A^{\prime}$ equal to the area of the screen wires.

The extremely good heat transfer from the spherecosted 100-mesh screen made it impossible to ob. tain coefficients for this material (see following discussion of errors).

\section{Errors in the Heat-Transfer Results}

Because of the finely divided porosity in most of tine materials being tested, the heat transfer is very gonc. Thus, the temperature of the fluid exiting the matrix is nearly equal to that of the matrix. [This is a particular problem at low flow velocities (low Re) for matrices of the small spheres.] It is difficult to determine this very small temperature difference, $\Delta \mathrm{T}$, accurately.

Small heat leaks can cool the outlet fluid making $\Delta T$ appear larger than it really is. Electrical heating of the screen near the thermocouple attachments can give a high screen-temperature reading (fluid cooling cannot occur there because the screen passages are blocked by the solder). Both of these effects cause underestimation of $h$. Fluid cooling of the thermocouples measuring screen temperature would cause underestimation of $\Delta T$ and over estimation of $h$.

For the sphere-coated 100 -mesh screen we expected $\Delta \mathrm{T}$ to be very small $(\approx 0.02 \mathrm{~K})$. The measurements gave a value near $-0.5 \mathrm{~K}$ (implies the exiting fluid was hotter than the screen). It was thus impossible to deduce $h$ for such excellent heat transfer.

If the heat-transfer experiment were run again, it would be helpful to cool the incoming fluid so that it is almost room temperature after being heated by the matrix; this would minimize heat leakage into the outlet fluid, making the measurement of $\Delta \mathrm{T}$ more accurate.

\section{ANALYSWS OF RESULTS}

The pressure drops through the fine screen-andsphere matrices seemed to be the same or a little smaller than those expected based on the scaling of results obtained for larger screen-and-sphere matrices. ${ }^{2}$
The heat-transfer measurements on the screens show a slightly higher $h$ tiuan scaling from the larger sizes.s $^{\text {s.8 }}$ would predict. For spheres, the very large values for $\mathrm{hA}^{\prime}$ make the measurements difficult, particularly at low flow rates; and so we believe the values of $h$ at low he in Fig. 16 are in error.

As a first step toward applying finely divided porous materials to magnetic refrigeraciors, a counterflow heat exchanger using these materials has been built. It has a value of $G \approx 1$ for helium gas at $77300 \mathrm{~Pa}(1 \mathrm{~atm})\left[\rho=0.008 \mathrm{~g} / \mathrm{cm}^{3}, \mu=4 \times 10^{-6} \mathrm{~Pa} \cdot \mathrm{g}\right.$ $\left(40 \times 10^{-6}\right.$ poise), $C_{p}=5.5 \mathrm{~J} / \mathrm{g} \cdot \mathrm{K}$, and $\left.\operatorname{Pr} \approx 1\right]$. As an example, let us compare the figure of merit $h A^{\prime} / P$ for n layers, $1 \mathrm{~cm}^{2}$ each, of 100 -mesh screen and a bed of $70-\mu \mathrm{m}$ spheres, $1 \mathrm{~cm}$ thick and $1 \mathrm{~cm}^{2}$ in area.

Using the definitions and the $d$ ta in Fig. 10 for 100 -mesh screen, we find $R e=11,0, f \approx 0.5$, and $P$ $=294 \mathrm{n}$. In Fig. 14, Re = 895; extrapolating or using Ref. 5 we find $\mathrm{hPr}^{2 / 8} \alpha / \mathrm{GC}_{\mathrm{p}}=0.04$, or $\mathrm{h}=0.67$. Because $A^{\prime} / A$ is $2.4 n$, we find for $A=1 \mathrm{~cm}^{2}$

$\mathrm{hA}^{\prime} /\left.\mathrm{P}\right|_{100 \text { mesh }}=5.5 \times 10^{-3}$.

Similarly, using Fig. 11 for spheres we find $R e=$ $350, f \approx 1.7$, and $P=1.21 \times 10^{s} \mathrm{~L}$. Also, using Fig. 16 we find $R e=240$; extrapolating the dashed curve or using Ref. 5 we find $h \mathrm{hr}^{2 / 8} \alpha / \mathrm{GC}_{\mathrm{p}}=0.038$, or $\mathrm{h}=\mathbf{0 . 4}$. Because $A^{\prime} / A=6 L(1-\alpha) / d_{p}=430 L$, then for $A=1$ $\mathrm{cm}^{2}$

$\mathrm{hA} /\left.\mathrm{P}\right|_{\text {spheres }}=1.4 \times 10^{-3}$.

This is a factor of 4 worse than the figure of merit for the screen. The $G$ dependence of $P$ and $h$ for the screens and spheres is similar for $G$ values near 1 , so 100-mesh screen will generally give better heat

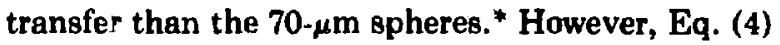
or Fig. 11 shows the strong dependence of $P$ on $\alpha$ for the spheres. If we increase $\alpha$ to 0.75 from $0.5, \mathrm{P}$ would drop by a factor of roughly $(1-\alpha) / \alpha^{\mathrm{s}}=0.68$. However, hA ${ }^{\prime}$ would drop only by a factor of $(1-\alpha) / \alpha$ $=0.33$, thus increasing $\mathrm{hA}^{\prime} / \mathrm{P}$ by a factor of 2 .

Let us compare the figures of merit for the 40 . mesh screen with and without sphere coating.

*Changing the particle size, $d_{b}$, does not improve the figure of merit because it is elmost independent of $d_{p}$ for $G$ near 1 (from Figs. 16 and 17 and $A^{\prime} \propto d_{p}{ }^{-1}$ ). 
Figure 17 suggest 3 (but does not prove) a roughly $25 \%$ improvement in 'hA' because of the sphere coating. The incomplete monolayer sphere coating decreased the velue of $\alpha_{\mathrm{r}}$ only slightly, so fruin Fig. 10 we expect only a slight increase in $P$. Thus hA'/P does not differ wiuch.

Let us also compare the figures of merit for the 100-mesh screen with and witheut sphere coating. Figure 5 shows that $P$ for 4 layers of coated 100-mesh screen is a factor of roughly 1.8 larger than that for 10 layers of the uncoated material; thus, $P$ per layer of coated screen is larger by a factor of 4.5. We were unable to deduce $h$ because of the excellent heat transfer. Thus we must estimate $h A^{\prime}$. By weight, we find that there are $0.058 \mathrm{~g} / \mathrm{cm}^{2}$ of spheres on the 100 . mesh screen. This is an area $A^{\prime}$ of $5.5 \mathrm{~cm}^{2}$ per $\mathrm{cm}^{2}$ of screen area $A$. But the screen area $A^{\prime}$ is 2.4 times $A$. Therefore, we have increased the total heatexchange area $A^{\prime}$ by a factor of $(5.5+2.4) / 2.4=3.3$. The discussion preceding Eqs. (24) and (25) suggests that $h$ for the screen is somewhat higher (by a factor of $0.67 / 0.4=1.7$ ) than that for the spheres, and that we might expect to increase $h A^{\prime}$ by a factor of $(2.4 \cdot 0.67+5.5 \cdot 0.4) / 2.4 \cdot 0.67)=2.4$. Thus, the spheres have probably decreased hA'/P by a factor of $2.4 / 4=0.6$.

In general, we found that screen, with its more open structure, is a better heat-transfer matrix than packed beds of spheres. As a result, fine screens are the primary heat-exchange media in the exchangers. being used in further work. ${ }^{7}$

\section{ACKNOWLEDGMENTS}

K. D. Williamsor provided a great deal of input to the initial stages of this work. He also provided most of the information needed to aliow comparison of our data with previous results. Most of the apparatus was designed and built by R. L. Cole. Conversations with $W$. $H$. Denton have also been helpful.

\section{REFERENCES}

1. S. S. Rosenblum, W. A. Steyert, and F. R. Fickett, "A Simple Method for Producing HighConductivity Copper for Low-Temperature Applications," to be published in Cryogeniç.

2. Robert H. Perry and Cecil H. Chilton, Chemical Engineers' Handbook, 5th ed. (McGraw-Hill, New York, 1973).

3. E. R. G. Eckert and R. M. Drake, Jr., Heat and Mass Transfer (McGraw-Hill, Now York, 1959).

4. W. M. Kays and A. L. London, Compact Heat Exchangers (McGraw-Hill, New ork, 1964).

5. J. E. Coppage and A. L. London, "Heat Transfer and Flow Friction Characteristics of Porous Media," Chem. Eng. Prng. 52, 57 (1956).

6. J. G. Knudsen and D. L. Katz, Fluid Dynamics and Heat Transfer (McGraw-Hill, New York, 1958).

7. W. A. Steyert and N. J. Stone: "Low-Flow. Velocity Fine-Screen Heat Exchangers and VaporCooled Current Leads," submitted for publication in Cryogenics. 